\title{
Activated biochar prepared from plaintain peels: Characterization and Rhodamine B adsorption data set
}

\author{
Folahan A. Adekola ${ }^{a}$, Suleiman B. Ayodele ${ }^{a}$, Adejumoke A. Inyinbor ${ }^{\mathrm{b}, *}$ \\ ${ }^{a}$ Industrial Chemistry department, University of Ilorin, P.M.B 1515, Ilorin, Nigeria \\ b Physical Sciences department, Landmark University, P.M.B 1001, Omu Aran, Nigeria
}

\section{A R T I C L E I N F O}

\section{Article history:}

Received 27 August 2018

Revised 25 November 2018

Accepted 29 November 2018

Available online 30 November 2018

\section{Keywords:}

Plantain peel

Biochar

Adsorption

Rhodamine B

\begin{abstract}
A B S T R A C T
The surface morphology and Surface Chemistry of plantain peel activated biochar (PPAB) viz-a-viz PPAB efficacy in Rhodamine $B(\mathrm{RhB})$ dye adsorption is presented in this data article. The surface morphology shows pores of various shapes and sizes consequence of activation. Surface Chemistry revealed functional groups such as $-\mathrm{OH}$ and $\mathrm{C}=\mathrm{O}$ of amide. Adsorption of $\mathrm{RhB}$ was observed to increase with increased $\mathrm{pH}$ and optimum adsorption was observed at $\mathrm{pH}$ of 7 with percentage removal of $54.78 \%$. Increase in temperature had negligible effect on $\mathrm{RhB}$ removal. RhB uptake increased with increase in PPAB dosage up to $0.3 \mathrm{mg} / \mathrm{L}$ and increased contact time aided $\mathrm{RhB}$ removal with optimum adsorption of $84.41 \mathrm{mg} / \mathrm{g}$ at $120 \mathrm{~min}$.
\end{abstract}

(C) 2018 Published by Elsevier B.V.

\section{Specifications Table}

\begin{tabular}{ll}
\hline $\begin{array}{l}\text { Subject area } \\
\text { Compounds }\end{array}$ & $\begin{array}{l}\text { Chemical Engineering } \\
\text { plaintain peels activated biochar (PPAB), Rhodamine B } \\
\text { (RhB) }\end{array}$ \\
Data category & Spectral, Images, graphs, modification procedure \\
Data acquisition format & SEM, FTIR, RhB adsorption data \\
Data type & Analyzed data \\
Procedure & Characterization data of PPAB were obtained from SEM, EDX, \\
& FTIR and other physicochemical parameters. \\
& Batch adsorption studies \\
& - pH was varied between 2 and 10, \\
& - Temperature was varied between 293 and $393 \mathrm{~K}$ \\
& - Contact time was 120 min \\
Data accessibility & Data accessible herein \\
\hline
\end{tabular}

\section{Rationale}

Adsorption using activated carbon is a preferred choice over other conventional wastewater treatment methods. It is characterized by simplicity of operation and efficient in the removal of very low concentration of pollutants [1]. However, the cost of activated carbon is a major disadvantage of the adsorption technique in wastewater treatment. The major source(s) of cost accumulation on activated carbons is usually from their precursors and treatment/preparation technique [2]. Hence,

\footnotetext{
* Corresponding author.

E-mail address: inyinbor.adejumoke@landmarkuniversity.edu.ng (A.A. Inyinbor).
} 
alternative precursor and methods of activated carbon preparation will go a long way to reduce cost thus making adsorption technique an economically friendly and efficient wastewater treatment technique [3].

The carbonaceous and lignocellulosic characteristic of agro wastes qualifies them both as lowcost adsorbent and a precursor for activated carbon preparation [4]. Interestingly, their carbon content can be enriched via carbonization and subsequent activation may create well developed pores which enhances adsorption efficiency [5]. Temperature, carbonization time and rate, chemical content in precursors and precursor types influence biochar porosity [6]. The chemical activation technique saves energy hence produces cheaper activated carbon compared with physical activation [7]. Chemically activated biochar also gives better yield, improved surface area and have the tendency of yielding biochar with surface functional group(s) [8]. Treated waste materials of many kinds have been found effective in the removal of inorganic metals [9, 10], organic dyes $[11,12]$ and pharmaceutical contaminants [13].

Plantain peel (PP) which is rich in carbon is about 30\% of the plantain fruit [14]. Huge volume of plantain peel is generated particularly in the southern part of Nigeria. PP is a waste without any economic value and it generally constitute environmental nuisance. Acids, bases and salts can be used as chemical activating agents. While several reports exist for biomass treatment with acids [11, 15], bases [16, 17], and salts such as sodium chloride [18] and Zinc chloride [19]. The use of salt such as Ferric nitrate is scarcely reported. Considering the capacity of iron in dye degradation [20] and the capacity of ferric salts to effectively enhance porosity [21] we activated PP biochar using Ferric nitrate (PPAB). This novel adsorbent which combines the effect of dye degradation with enhanced porosity is prepared for efficient treatment of RhB dye containing wastewater. Hence, prepared activated biochar was used for the removal of RhB from aqueous solution. The characterization and adsorption data is herein presented.

\section{Procedure}

\subsection{Biochar preparation}

Plantain peels $(20 \mathrm{~g})$ was transferred into silica crucible and heated in an air-tight furnace (Garbolite CWF 1300) operated at $500{ }^{\circ} \mathrm{C}$ for 5 hours. Obtained carbon material were carefully transferred to an airtight container, labelled PPB and kept for further treatment.

\subsection{Biochar activation}

Equal mass/volume ratio of PPB and $\mathrm{Fe}\left(\mathrm{NO}_{3}\right)_{3}$ were mixed in a crucible. The crucible with its content was heated at $750 \pm 50{ }^{\circ} \mathrm{C}$ for five min. Activated PPB samples were allowed to cool to room temperature, it was subsequently washed with distilled water until neutral $\mathrm{pH}$ was obtained. It was dried in an oven operated at $110{ }^{\circ} \mathrm{C}$ for 8 hours. Activated biochar was labelled PPAB.

\subsection{Adsorption studies}

The characteristics and nature of adsorbate in solution is greatly influenced by various adsorption operational parameters. Here, we varied the solution $\mathrm{pH}$, contact time, adsorbent dosage and temperature. $1 \mathrm{~g} / \mathrm{L}$ dosage, $30 \mathrm{mg} / \mathrm{L}$ concentration, 150 revolution per minute (rpm) were fixed conditions. $\mathrm{pH}$ was varied between 2 and 9, temperature between 303 and 333 ${ }^{\circ} \mathrm{K}$ and contact time ran from 1 to $120 \mathrm{~min} .30 \mathrm{~cm}^{3}$ adsorbate solution was agitated with the specified mass of adsorbent in an Erlenmeyer flask, this was placed in a temperature controlled water bath shaker and agitated until equilibrium. The unadsorbed dye molecules were separated from the adsorbent by centrifuge and unadsorbed and residual concentration was determined using a Beckman Coulter Du 730 Life science UV-Visible Spectrophotometer operated at $554 \mathrm{~nm}$.

\subsection{Data analysis}

Quantity adsorbed and removal efficiency was calculated with equation I and 2 respectively.

$$
\begin{aligned}
& \boldsymbol{q}_{t}=\frac{\left(\boldsymbol{C}_{\boldsymbol{i}}-\boldsymbol{C}_{\boldsymbol{t}}\right) \times \boldsymbol{V}}{\boldsymbol{M}} \\
& \% \text { Removal }=\frac{\left(\boldsymbol{C}_{\boldsymbol{i}}-\boldsymbol{C}_{\boldsymbol{f}}\right)}{\boldsymbol{C}_{\boldsymbol{i}}} \times 100
\end{aligned}
$$

$C_{i}, C_{t}$ and $C_{f}$ are initial adsorbate concentration, adsorbate concentration at time $t$ and final adsorbate concentration respectively, all in $\mathrm{mg} / \mathrm{L}$. $\mathrm{V}$ is the volume of adsorbate used in liters and $\mathrm{M}$ is the mass of adsorbent in grammes.

\subsection{Data, value and validation}

\subsubsection{PPAB surface chemistry and surface morphology}

Absorption peaks were observed at $3360 \mathrm{~cm}^{-1}$ charateristics of $-\mathrm{OH}$ vibrations, $1584 \mathrm{~cm}^{-1}$ which corresponds to $\mathrm{C}=\mathrm{O}$ of amide and/or $\mathrm{NH}_{2}$ scissoring and $1362 \mathrm{~cm}^{-1}$ which corresponds to $\mathrm{CH}_{3}$ bending vibrations. Minor peaks which occurred at 


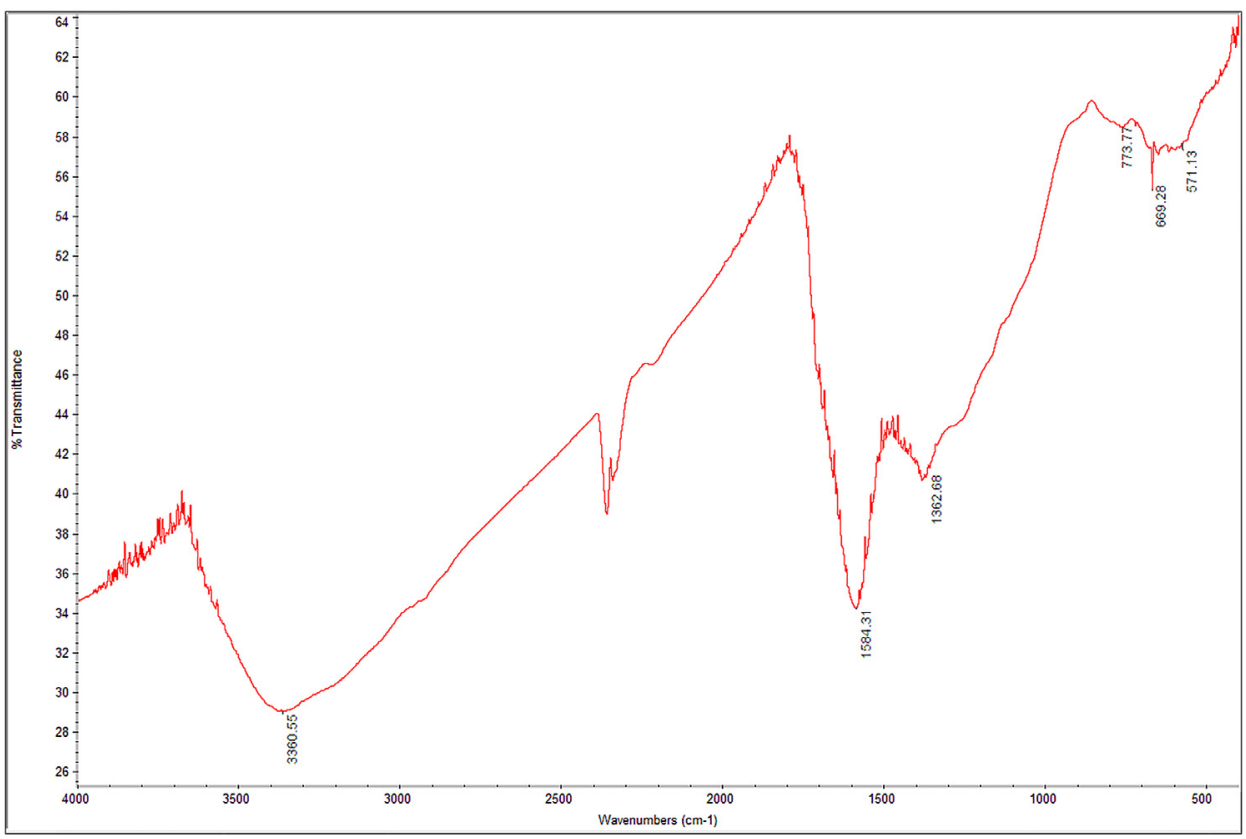

Fig. 1. FTIR spectrum of PPAB.

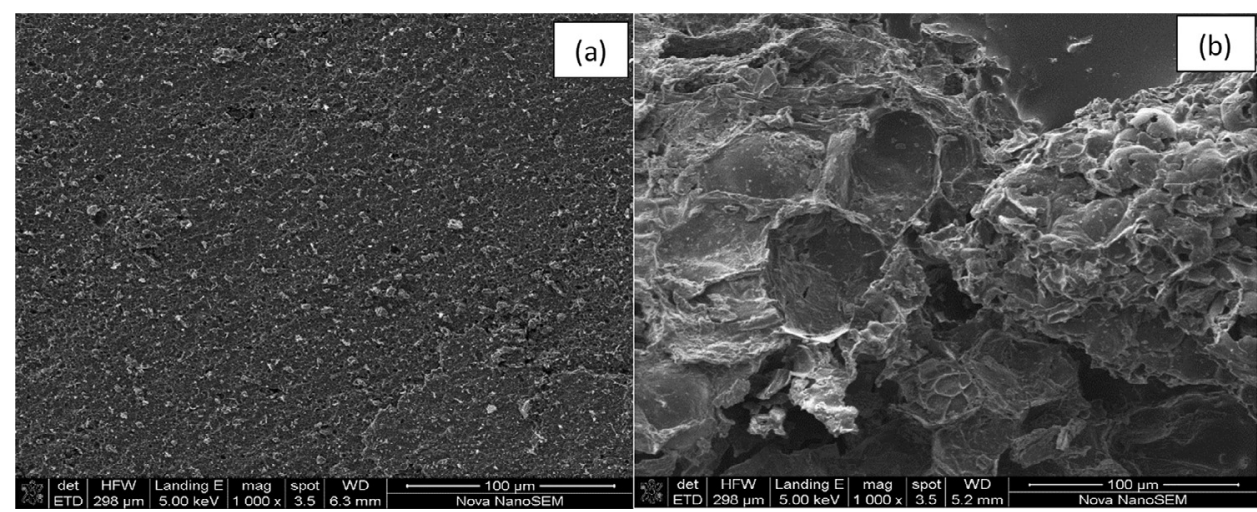

Fig. 2. SEM image of PPB (a) and PPAB (b).

773 and $667 \mathrm{~cm}^{-1}$ may be allocated to aromatic vibrations (Fig. 1). The surface morphology of PPB and PPAB is compared in Fig. 2. Pores of various shapes and sizes developed on adsorbent surface after activation. PPAB conains high carbon content with about $20 \%$ oxygen. Fe content was $2.3 \%$, Fe may have been introduced via the activating agent. Other metals such as $\mathrm{Na}, \mathrm{Mg}, \mathrm{Ca}$ and $\mathrm{K}$ were also present in PPAB (Fig. 3).

\subsubsection{Adsorption data}

The effects of various operational parameters on RhB removal using PPAB is shown in Fig. 4. Percentage adsorption increase with increased $\mathrm{pH}$ and reached maximum at $\mathrm{pH}$ of 7 then slightly decreased (Fig. 4a). Protonation of the adsorbent surface occurs at low $\mathrm{pH}$ hence repulsion between the cationic dye RhB and positively charged adsorbent surface. As solution $\mathrm{pH}$ increased, the adsorbent surface is continuously deprotonated and attraction between the negatively charged adsorbent surface and cationic dye results in increased adsorption. This data agrees with previously reported work [22]. Continuous bombardment of RhB molecule on the surface of the adsorbent aids adsorption hence RhB removal increased with time (Fig. 4b). Rapid adsorption was observed within the first 40 min followed by a gradual RhB uptake and then negligible increase in quantity adsorbed was observed. Increased adsorption surface sites results in increased percentage removal between $0.1 \mathrm{mg} / \mathrm{L}$ and $0.3 \mathrm{mg} / \mathrm{L}$ dosage (Fig. 4c). Further increase in adsorbent dosage yielded no increase in percentage adsorption. This may be attributed to overlay of adsorbent as well as saturation of adsorption sites [23]. Percentage RhB removal slightly increased with temperature (Fig. 4d). Activation of adsorption site via increased temperature may have been responsible for this increase [24]. 


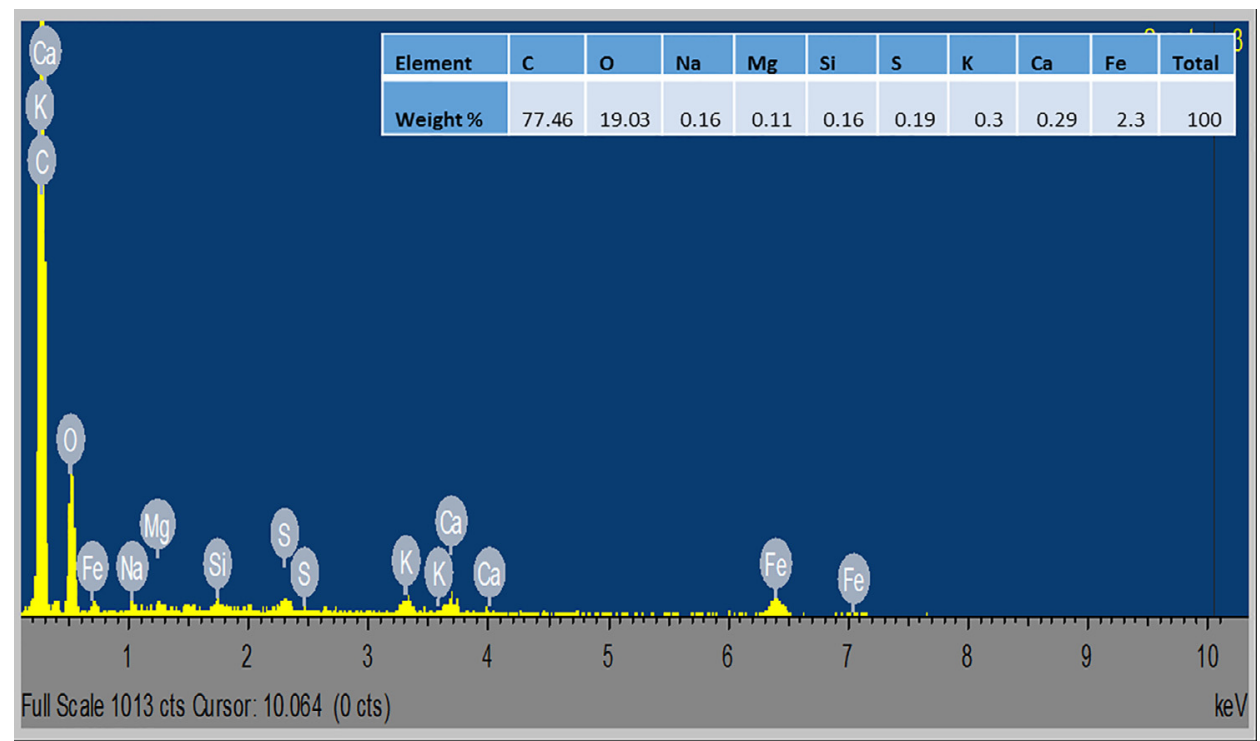

Fig. 3. EDX spectrum of PPAB.
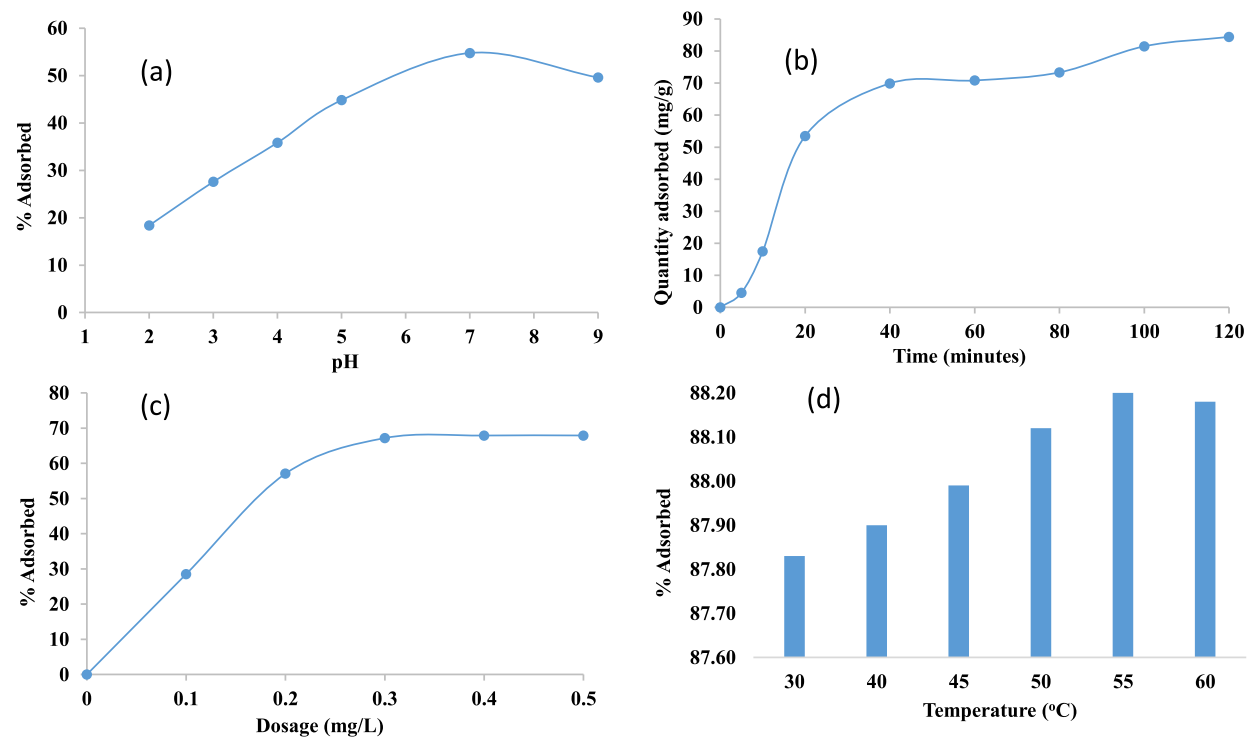

Fig. 4. Effects of pH on RhB uptake (a), time on RhB uptake (b), dosage on RhB uptake (c) and temperature on RhB uptake (d) onto PPAB.

\section{References}

[1] K. Toumi, Y. Benguerba, A. Erto, G.L. Dotto, M. Khalfaoui, C. Tiar, S. Nacef, A. Amrane, Molecular modeling of cationic dyes adsorption on agricultural Algerian olive cake waste, J. Mol. Liquids 264 (2018) 127-133.

[2] G.Z. Kyzas, E.A. Deliyanni, K.A. Matis, Activated carbons produced by pyrolysis of waste potato peels: Cobalt ions removal by adsorption, Colloids Surfaces A 490 (2016) 74-83.

[3] G.Z. Kyzas, A.C. Mitropoulos, Zero-Cost Agricultural wastes as sources for activated carbons synthesis: lead ions removal from wastewaters, Proceedings 2 (2018) 652 doi:103390/proceedings2110652.

[4] Y. Dai, Q. Sun, W. Wang, L. Lu, M. Liu, J. Li, S. Yang, Y. Sun, K. Zhang, J. Xu, W. Zheng, Z. Hu, Y. Yang, Y. Gao, Y. Chen, X. Zhang, F. Gao, Y. Zhang, Utilizations of agricultural waste as adsorbent for the removal of contaminants: A review, Chemosphere 211 (2018) 235-253.

[5] G.D. Vyavahare, R.G. Gurav, P.P. Jadhav, R.R. Patil, C.B. Aware, J.P. Jadhav, Response surface methodology optimization for sorption of malachite green dye on sugarcane bagasse biochar and evaluating the residual dye for phyto and cytogenotoxicity, Chemosphere 194 (2018) 306-315.

[6] S. You, Y.S. Ok, S.S. Chen, D.C.W. Tsang, E.E. Kwon, J. Lee, C. Wang, A critical review on sustainable biochar system through gasification: Energy and environmental applications, Bioresour. Technol. 246 (2017) 242-253.

[7] R.K. Liew, E. Azwar, P.N.Y. Yek, X.Y. Lim, C.K. Cheng, J. Ng, A. Jusoh, W.H. Lam, M.D. Ibrahim, N.L. Ma, S.S. Lam, Microwave pyrolysis with KOH/NaOH mixture activation: A new approach to produce micro-mesoporous activated carbon for textile dye adsorption, Bioresour. Technol. 266 (2018) 1-10.

[8] M.J.P. Brito, C.M. Veloso, L.S. Santos, R.C.F. Bonomo, R.D.I Fontan, Adsorption of the textile dye Dianix® royal blue CC onto carbons obtained from 
yellow mombin fruit stones and activated with $\mathrm{KOH}$ and H3PO4: Kinetics, adsorption equilibrium and thermodynamic studies, Powder Technol. (2018), doi:10.1016/j.powtec.2018.08.017.

[9] A.A. Inyinbor, F.A. Adekola, A.O. Dada, A.P. Oluyori, G.A. Olatunji, O.F. Fanawopo, T.A. Oreofe, T.O. Abodunrin, Novel acid treated biomass: Applications in $\mathrm{Cu}^{2+}$ scavenging, Rhodamine $\mathrm{B} / \mathrm{Cu}^{2+}$ binary solution and real textile effluent treatment, Environ. Technol. Innovation 13 (2019) 37-47, doi:10.1016/ j.eti.2018.10.006.

[10] N.E. Davila-Guzman, F.J. Cerino-Córdova, M. Loredo-Cancino, J.R. Rangel-Mendez, R. Gómez-González, E. Soto-Regalado, Studies of adsorption of heavy metals onto spent coffee ground: equilibrium, regeneration, and dynamic performance in a fixed-bed column, Int. J. Chem. Eng. (2016) Article ID 9413879, doi:10.1155/2016/9413879.

[11] A.A. Inyinbor, F.A. Adekola, G.A. Olatunji, Liquid phase adsorption of Rhodamine B onto acid treated Raphia hookerie epicarp: Kinetics, Isotherm and thermodynamics studies, South African J. Chem. 69 (2016) 218-226.

[12] C. Manera, A.P. Tonello, D. Perondi and M. Godinho; Adsorption of leather dyes on activated carbon from leather shaving wastes: kinetics, equilibrium and thermodynamics studies; Environ. Technol., doi:10.1080/09593330.2018.1452984.

[13] G.Z. Kyzas, E.A. Deliyanni, Modified activated carbons from potato peels as green environmental-friendly adsorbents for the treatment of pharmaceutical effluents, Chem. Eng. Res. Design (2015) 97135 -144.

[14] K.B. Arun, F. Persia, P.S. Aswathy, J. Chandran, M.S. Sajeev, P. Jayamurthy, P. Nisha, Plantain peel - a potential source of antioxidant dietary fibre for developing functional cookies, J. Food Sci. Technol. 52 (10) (2015) 6355-6364.

[15] A.A. Inyinbor, F.A. Adekola, G.A. Olatunji, Adsorption of Rhodamine B dye from aqueous solution on Irvingia gabonensis biomass: Kinetics and thermodynamics studies, South Africa J. Chem. South Africa J. Chem. 68 (2015) 115-125.

[16] Z. Li, H. Deng, L. Yang, G. Zhang, Y. Li, Y. Ren, Influence of potassium hydroxide Activation on characteristics and environmental risk of heavy metals in chars derived from municipal sewage sludge, Bioresour Technol. 256 (2018) 216

[17] M.A. Islam, A. Benhouria, M. Asif, B.H. Hameed, Methylene blue adsorption on factory-rejected tea activated carbon prepared by conjunction of hydrothermal carbonization and sodium hydroxide activation processes, J. Taiwan Instit. Chem. Eng. 52 (2015) 57-64.

[18] C.C. Okoye, O.D. Onukwuli, C.F. Okey-Onyesolu; Utilization of salt activated Raphia hookeri seeds as biosorbent for Erythrosine B dye removal: Kinetics and thermodynamics studies (2018), doi:10.1016/j.jksus.2017.11.004.

[19] H. Sayğılı, F. Güzel, High surface area mesoporous activated carbon from tomato processing solid waste by zinc chloride activation: process optimization, characterization and dyes adsorption, J. Cleaner Prod. 113 (2016) 995-1004.

[20] K.K. Rubeena, P.H.P. Reddy, A.R. Laiju and P.V. Nidheesh; Iron impregnated biochars as heterogeneous Fenton catalyst for the degradation of acid red 1 dye; 226:320-328 (2018)

[21] X. Yang, G. Xu, H. Yu, Removal of lead from aqueous solutions by ferric activated sludge-based adsorbent derived from biological sludge, Arabian J. Chem. (2016), doi:10.1016/j.arabjc.2016.04.017.

[22] F.H.M. Sattar, W. Chinpa, O. Sirichote, Kinetics and thermodynamics of Rhodamine B adsorption by gelatin/activated carbon composite beads, Colloids Surf. A 513 (2017) 259-266.

[23] A.E. Pirbazari, E. Saberikhah, S.S. HabibzadehKozani, Fe $3 \mathrm{O}_{4}-$ wheat straw: preparation, characterization and its application for methylene blue adsorption, Water Resour. Ind. 7-8 (2014) 23-37.

[24] A.A. Inyinbor, F.A. Adekola, G.A. Olatunji, Kinetic and thermodynamic modeling of liquid phase adsorption of Rhodamine B dye onto Raphia hookerie fruit epicarp, Water Resour. Ind. 15 (2016) 14-27. 